\title{
Analysis of Wind Energy Resource Potentials in Nansha Guangzhou
}

\author{
Huang DONG \\ Department of Electrical and Electronic Engineering \\ The University of Hong Kong \\ e-mail: u3533554@connect.hku.hk
}

\author{
Wilton Wai-Tung Fok \\ Department of Electrical and Electronic Engineering \\ The University of Hong Kong \\ e-mail: wilton@hku.hk
}

\begin{abstract}
Nansha is located in Guangzhou and is planned as the China(Guangdong) Pilot Free Trade Zone after Dec.2014, the electricity demand is believed to increase and exceed the capacity of the existing three thermal power plants in the near future. With the purpose of achieving a better energy structure and environmental friendly development in Nansha, this research was carried out to analysis the wind energy resource potentials at Huangshanlu Forest Park in this area. Resource measurement method as well as the result of resource potentials assessment were summarized with help of MATLAB and WindRosePRO. It draw a conclusion that northeastern wind was the main contributor, wind resource was unstable and dependable on seasons, extremely abundant in February, March and April but just available in other months. However, variation between day and night was slight. So it's possible to build small wind energy power plant for district power supply and sightseeing. Besides, domestic and public utilization of mini type wind turbine is also available.
\end{abstract}

Keywords- Wind Energy; Resource Potentials; MATLAB; WindRosePRO

\section{RESEARCH BACKGROUND AND SIGNIFICANCE}

Nansha (NS) locates in the southernmost of Guangzhou $\left(22.8016^{\circ} \mathrm{N}, 113.5252^{\circ} \mathrm{E}\right)$ and is planned as the China(Guangdong) Pilot Free Trade Zone after Dec.28 th, 2014 , covering a total area of $783.86 \mathrm{~km} 2$. It is the geographical center of the Great Pearl River Delta Region, and an important hub for more than 10 neighbor cities of Pearl River port group. NS is just 38 sea miles away from Hong Kong and 41 sea miles from Macao.

Among 2005 to 2015, GDP at NS presented remarkable growth shown in Figure 1. While the ratio of NS and Guangdong's GDP revealed a sudden increase between 2011 and 2012, benefiting from the government policies on the planning of Nansha New District, after which a steady growth in GPD was achieved from 2012 to 2015. As a consequence of GDP growth, total electricity consumption increased from 0.873 to 5.398 billion $\mathrm{kWh}$ in 2005 to 2014 , with an average annual growth rate of $22.44 \%$ [1] .

The rapid development in NS results an increasing energy supply accordingly, which is believed to exceed the capacity of the existing three thermal power plants in the near future. On the basis of the research from Zhong Zequan 1 , the prospective saturation load would be about $8510 \mathrm{MW}$ in 2030. Therefore, to achieve sufficient electricity supply, construct a more proper and environmental friendly energy structure at NS would be one of the main themes during the region planning.
In this study, wind energy resource potentials were analyzed at NS, aiming to help the exploitation and utilization of renewable energy at NS.

All manuscripts must be in English. These guidelines include complete descriptions of the fonts, spacing, and related information for producing your proceedings manuscripts. Please follow them and if you have any questions.

This template provides authors with most of the formatting specifications needed for preparing electronic versions of their papers. All standard paper components have been specified for three reasons: (1) ease of use when formatting individual papers, (2) automatic compliance to electronic requirements that facilitate the concurrent or later production of electronic products, and (3) conformity of style throughout a conference proceedings. Margins, column widths, line spacing, and type styles are built-in; examples of the type styles are provided throughout this document and are identified in italic type, within parentheses, following the example. PLEASE DO NOT RE-ADJUST THESE MARGINS. Some components, such as multi-leveled equations, graphics, and tables are not prescribed, although the various table text styles are provided. The formatter will need to create these components, incorporating the applicable criteria that follow.

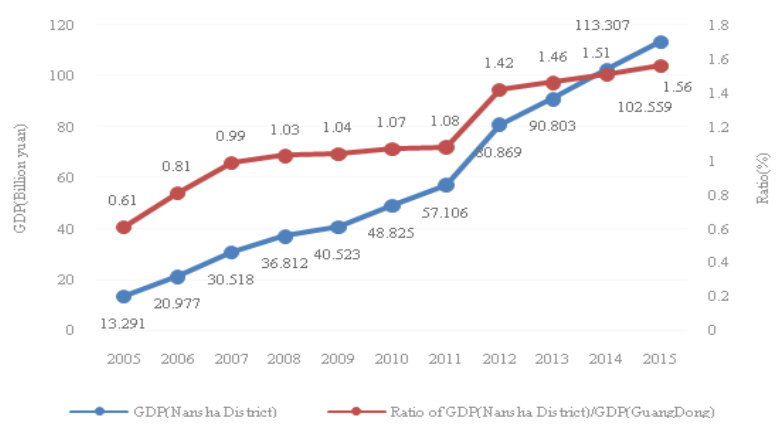

Figure 1. Growth of GDP at Nansha.

\section{METHODOLODY FOR WIND ENERGY RESOURCE POTENTIALS MEASUREMENT}

Wind energy resource can be measured in the flow shown in Figure 2[2,3], and assessed according to Table $1[3]$. Besides, valid wind power density (VWPD) at $10 \mathrm{~m}$ and $70 \mathrm{~m}$ height can be calculated as the following two methods:

(i) M1: calculated by windrose: 
where

$$
V W P D=\frac{1}{2} \sum f_{\alpha} \rho_{j} v_{\alpha}^{3}
$$

f $\alpha$ : frequency of valid wind speed interval $\alpha$.

$v \alpha$ : weighted average of valid wind speed interval $\alpha$.

рj: average air density of month $\mathrm{j}(\mathrm{kg} / \mathrm{m} 3)$, can be calculated by:

$$
\rho_{j}=\frac{1.276}{1+0.00366 t_{j}}\left(\frac{p-0.378 e_{j}^{*}}{1000}\right)
$$

where

tj: average temperature of month $\mathrm{j}\left({ }^{\circ} \mathrm{C}\right)$.

p: local air pressure(hpa).

ej*: average water vapor pressure(hpa).

Besides, when the average water vapor pressure can't be referred, it can be roughly assumed as saturated water vapor pressure and calculated by the following Goff-Gratch equation [4]:

$$
\begin{aligned}
\log e_{j}= & -7.90298\left(\frac{T_{s t}}{T_{j}}-1\right)+5.02808 \log \left(\frac{T_{s t}}{T_{j}}\right)-1.3816 \times 10^{-7}\left(10^{11.344\left(1-\frac{T_{j}}{T_{s t}}\right)}-1\right) \\
& +8.1328 \times 10^{-3}\left(10^{-3.49149\left(\frac{T_{s t}}{T_{j}}-1\right)}-1\right)+\log e_{s t}^{*}
\end{aligned}
$$

where

ej : Saturated water vapor pressure (hpa).

Tst: local steam-point temperature(K).
Tj: average temperature of month $\mathrm{j}(\mathrm{K})$. est*: local steam-point pressure(hpa).

(ii) M2: calculated by all data:

$$
V W P D=\frac{1}{2 N} \sum \rho_{j} v_{s}^{3}
$$

where

$\mathrm{N}$ : hours of valid wind speed in month $\mathrm{j}(\mathrm{h})$.

$\rho j$ : average air density of month $\mathrm{j}(\mathrm{kg} / \mathrm{m} 3)$.

vs: valid wind speed at $70 \mathrm{~m}$ height, can be calculated by:

$$
v_{70}=v_{10} \times\left(\frac{70}{10}\right)^{\alpha}
$$

where

v70: wind speed at $70 \mathrm{~m}$ height $(\mathrm{m} / \mathrm{s})$.

v10: wind speed at $10 \mathrm{~m}$ height $(\mathrm{m} / \mathrm{s})$.

$\alpha$ : rate of change in horizontal wind speed of height, known as the wind shear, can be valued as $1 / 7$ if assessment is based on meteorological data3.

So the relation of VWPD at $10 \mathrm{~m}$ and $70 \mathrm{~m}$ height is:

$$
V W P D_{10 m}=\frac{V W P D_{70 m}}{7^{\left(\frac{1}{7}\right)^{3}}}=\frac{V W P D_{70 m}}{2.3024}
$$

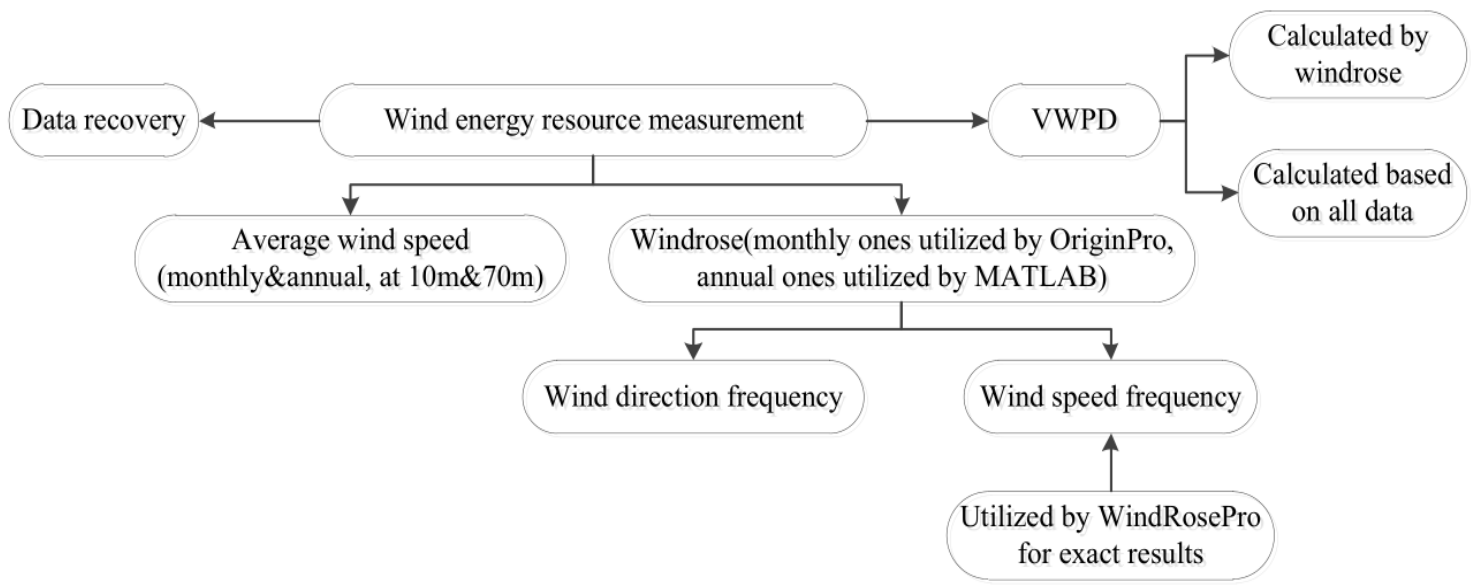

Figure 2. Flow chart of wind energy resource measurement.

TABLE I. GRADES OF WIND ENERGY RESOURCE ABUNDANCE AT 10M HEIGHT.

\begin{tabular}{ccc}
\hline Valid Wind Power Density $\left(\mathrm{W} / \mathrm{m}^{2}\right)$ & Annual Effective Hours(hrs) & Level \\
\hline$\geq 200$ & $\geq 5000$ & Extremely abundant \\
$150<\mathrm{VWPD}<200$ & $4000<\mathrm{AEH}<5000$ & Abundant \\
$50<\mathrm{VWPD}<150$ & $2000<\mathrm{AEH}<4000$ & Available \\
$\leq 50$ & $\leq 2000$ & Lacking \\
\hline
\end{tabular}




\section{RESUlts OF Wind ENERGY RESOURCE POTENTIALS ASSESSMENT}

According to the related research [3], wind energy is not abundant at $10 \mathrm{~m} \sim 60 \mathrm{~m}$ height at Shiqichong, NS (84.0 148.6W/m², location shown in Figure3). Nevertheless, based on the meteorological data provided from Guangzhou meteorological data sharing network hosted by Guangzhou Meteorological Service (GMS), Huangshanlu Forest Park (HSFP, location shown in Figure 3) shows more potential in wind energy exploitation at NS.

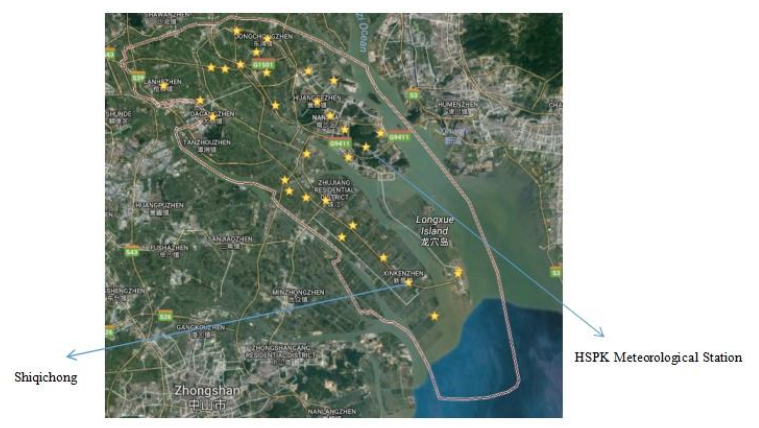

Figure 3. Thirty-one meteorological stations at NS.

The resource study at HSFP was based on original statistics of wind speed per hour that was collected at HSFP Meteorological Station by GMS from Aug. $1^{\text {st }}, 2015$ to July $31^{\text {st }}, 2016$. Besides, average temperature per month was also provided by GMS, and other parameters are shown in Table 2.

TABLE II. PARAMETERS USED IN WIND ENERGY ASSESSMENT

\begin{tabular}{llll}
\hline Altitude & $\mathrm{p}$ & $\mathrm{T}_{\mathrm{st}}$ & $\mathrm{e}_{\mathrm{st}}{ }^{\mathrm{*}}$ \\
\hline $392 \mathrm{~m}$ & $966.8 \mathrm{hpa}$ & $373.15 \mathrm{~K}$ & $1013.25 \mathrm{hpa}$ \\
\hline
\end{tabular}

After the assessment, number of valid data records of wind speed from Aug. $1^{\text {st }}, 2015$ to July $31^{\text {st }}, 2016$ was 8512 . Date Recovery of wind speed was $96.90 \%$. Apart from this, monthly and annual average wind speeds at $10 \mathrm{~m}$ and $70 \mathrm{~m}$ height were calculated and shown in Figure 4, which reveal that winter and spring (Dec.2015 to May 2016) contributed more wind power to HSFP though it met a "V-shaped" rebound on Mar.2016.

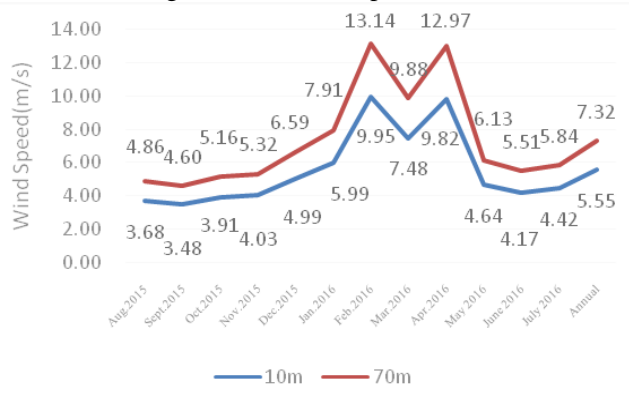

Figure 4. Average wind speed at $10 \mathrm{~m}$ and $70 \mathrm{~m}$ height.
Annual wind rose was drawn in Figure 5 utilized by MATLAB with help from Daniel Pereira, which indicated that wind from northeast(accounted for 36\% ) was abundant than that from southeast(28\%) and southwest $(20 \%)$. And according to Figure 6 utilized by WindRosePro, wind speed frequency were $15.3 \% \quad(3.5 \mathrm{~m} / \mathrm{s} \sim 5.0 \mathrm{~m} / \mathrm{s}), \quad 43.2 \%$ $(5.0 \mathrm{~m} / \mathrm{s} \sim 10.0 \mathrm{~m} / \mathrm{s}), \quad 10.4 \% \quad(10.0 \mathrm{~m} / \mathrm{s} \sim 15.0 \mathrm{~m} / \mathrm{s})$ and $6.2 \%$ $(15.0 \mathrm{~m} / \mathrm{s} \sim 20.5 \mathrm{~m} / \mathrm{s})$ at $70 \mathrm{~m}$ height this year. As a supplementary, Weibull Distribution of wind speed frequency at $70 \mathrm{~m}$ height was shown in Figure 7 utilized by WindRosePro, indicating that actual values had highly fitting with the model among the wind speed between $10.0 \mathrm{~m} / \mathrm{s}$ and $25.0 \mathrm{~m} / \mathrm{s}$.

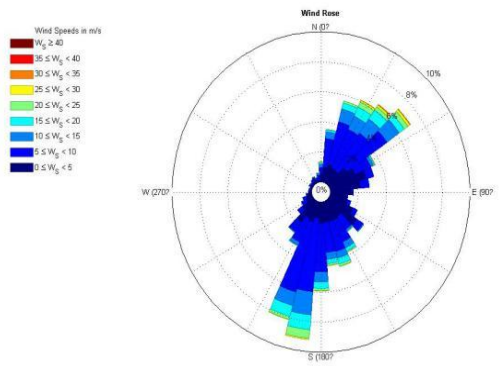

Figure 5. Annual wind rose at $70 \mathrm{~m}$ height

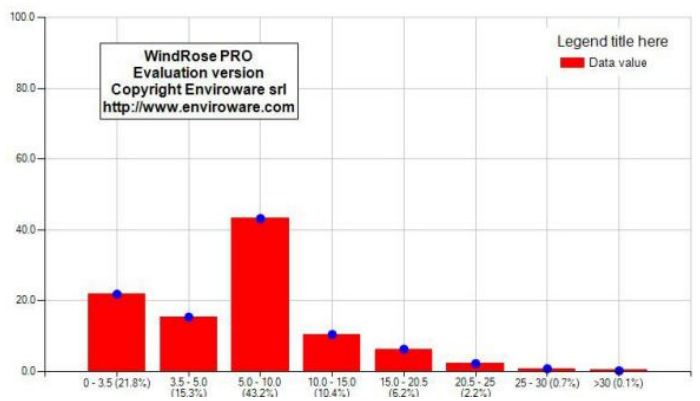

Figure 6. Wind speed frequency at $70 \mathrm{~m}$ height.

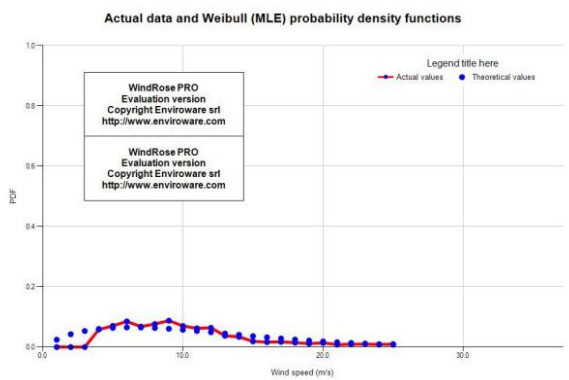

Figure 7. Weibull Distribution of wind speed frequency at $70 \mathrm{~m}$ height.

Above all, using the wind rose data, annual VWPD of HSFP at $10 \mathrm{~m}$ height was $188.16 \mathrm{~W} / \mathrm{m}^{2}$. If all data were considered, it was $228.87 \mathrm{~W} / \mathrm{m}^{2}$.In the light of Table 1 , the grade of wind energy resource abundance at HSFP was 
between abundant and extremely abundant.These results were 2.24 2.72 times higher than that at Shiqichong $(84.0 \mathrm{~W} / \mathrm{m} 2)$. And the effective hour (6359 6597) was $1.08 \sim 1.13$ times more. However, it's important to note that data of Oct. 4th, 2015 Oct.5th, 2015 were excluded for eliminating the influence of typhoon Mujigae.

But according to the results displayed in Figure 8, wind power resource in winter and spring (Dec.2015-May 2016) was at extremely abundant level $\left(705.00 \mathrm{~W} / \mathrm{m} 2 \sim 868.33 \mathrm{~W} / \mathrm{m}^{2}\right)$, but just reached available level in summer and fall $\left(161.46 \mathrm{~W} / \mathrm{m} 2 \sim 272.50 \mathrm{~W} / \mathrm{m}^{2}\right)$. Compared with other months, wind energy was extremely abundant in February, March and April. If the contributions from these 3 months are not considered, the average annual VWPD of HSFP at $10 \mathrm{~m}$ height is just $89.88 \mathrm{~W} / \mathrm{m} 2$ and $104.75 \mathrm{~W} / \mathrm{m} 2$, which is merely available. So the wind energy at HSFP was unstable and dependable on seasons.

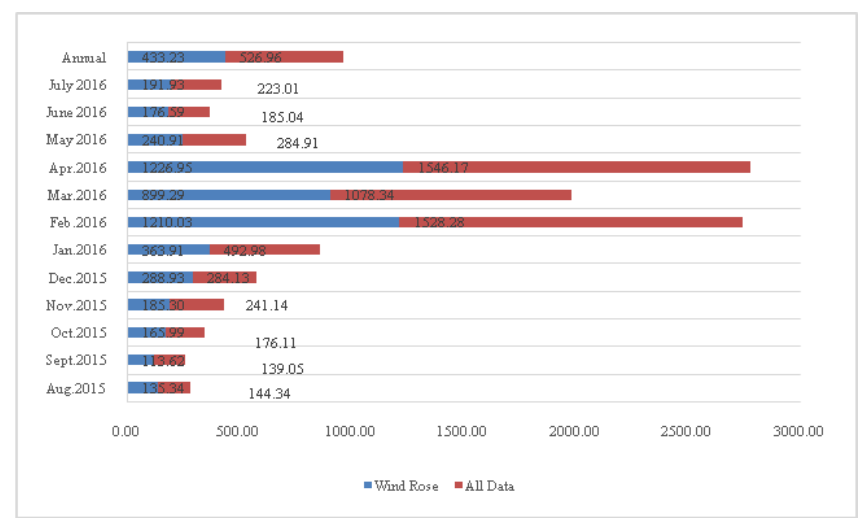

Figure 8. VWPD at $70 \mathrm{~m}$ height based on wind rose and all data $\left(\mathrm{W} / \mathrm{m}^{2}\right)$.

On the other hand, as shown in Figure 9, variation of monthly valid wind speed and VWPD between day and night was slight, but became significant on February, March and April in 2016.

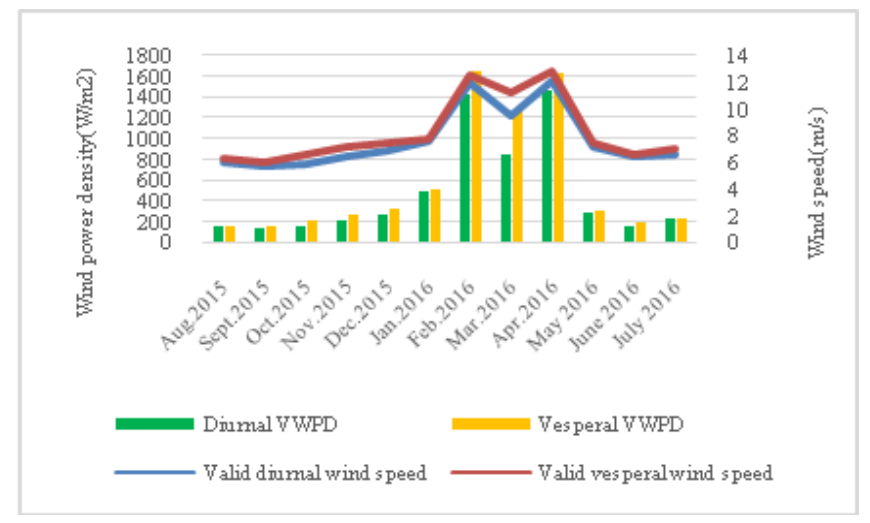

Figure 9. Variation of monthly valid wind speedand VWPD between day and night.

\section{DEVIATION ANALYSIS}

(i) This analysis was just based on one-year data(Aug. 1st, 2015 to July $31^{\text {st }}, 2016$ ) at HSFP Meteorological Station that provided by GMS, which was not wide and many enough to allow convincing conclusions to be drawn. So it's necessary to analyze another 5 7 years' statistics to complete a applicable research.

(ii) Wind shear $\alpha$ was valued as $1 / 7$ referred to the related research [3]. To get the more accurate results, anemometer tower is required to build and collect 4 6 different heights' wind data, instead of theoretical calculation.

(iii) Turbulence intensity couldn't be calculated for the insufficient data and it must be figured out and taken into consideration of the real wind farm construction, with the pulsating wind speed data measured per 3 seconds from the anemometer tower.

(iv) Spot investigation is necessary for the construction. Apart from the wind measurement results, geographical conditions and humanistic environment are also important factors that we have to consider before construction.

(v) This research just focuses on the wind resources measurement at HSFP. It is possible that there are other places which show more potential in wind energy exploitation at NS, especially some offshore areas.

\section{CONCLUSION}

(i) Annual wind speed at $10 \mathrm{~m}$ and $70 \mathrm{~m}$ height was $5.55 \mathrm{~m} / \mathrm{s}$ and $7.32 \mathrm{~m} / \mathrm{s}$ respectively, winter and spring (Dec.2015 to May 2016) contributed more wind power to HSFP. At HSFP, wind from northeast was the main contributor, valid wind speed frequency were $15.3 \%$ $(3.5 \mathrm{~m} / \mathrm{s} \sim 5.0 \mathrm{~m} / \mathrm{s}), \quad 43.2 \% \quad(5.0 \mathrm{~m} / \mathrm{s} \sim 10.0 \mathrm{~m} / \mathrm{s}), \quad 10.4 \%$ $(10.0 \mathrm{~m} / \mathrm{s} \sim 15.0 \mathrm{~m} / \mathrm{s})$ and $6.2 \%(15.0 \mathrm{~m} / \mathrm{s} \sim 20.5 \mathrm{~m} / \mathrm{s})$ at $70 \mathrm{~m}$ height from year 2015 to 2016. Besides, Weibull Distribution of wind speed frequency at $70 \mathrm{~m}$ height was highly fitting with the model among the wind speed between $10.0 \mathrm{~m} / \mathrm{s}$ and $25.0 \mathrm{~m} / \mathrm{s}$.

(ii) According to the wind rose data, annual VWPD of HSFP at $10 \mathrm{~m}$ height was $188.16 \mathrm{~W} / \mathrm{m} 2$ with effective hour of 6359. If all data were considered, the annual VWPD was $228.87 \mathrm{~W} / \mathrm{m}^{2}$ with effective hour of 6597 , the wind energy resource was considered as between abundant and extremely abundant. Such resource was especially abundant from February to April when the season changes from winter to spring.

(iii) But if the contributions from these 3 months were not considered, the average annual VWPD of HSFP at $10 \mathrm{~m}$ height was just $89.88 \mathrm{~W} / \mathrm{m} 2$ and $104.75 \mathrm{~W} / \mathrm{m}^{2}$, which was merely available. So the wind energy at HSFP was unstable and dependable on seasons. However, variation of monthly valid wind speed and VWPD between day and night was slight, but became significant on February, March and April in 2016.

(iv) It's possible to build small wind energy power plant for district power supply and sightseeing. Besides, domestic and public utilization of mini type wind turbine is also available. 


\section{ACKNOWLEDGMENT}

Thanks for Guangzhou Meteorological Service to share the data of wind speed per hour that collected at HSFP Meteorological Station (located at $22.784^{\circ} \mathrm{N}, 113.561^{\circ} \mathrm{E}$, the height is 392m) from Aug.1st, 2015 to July 31st, 2016 and the average temperature per month. Thanks for Daniel Pereira to help the drawing of windrose utilized by MATLAB.

\section{REFERENCES}

[1] ZHONG Zequan, Research on NanshaNew District's long-term planning of power grid, $\mathrm{PhD}$ thesis,South China University of Technology, (SCUT, China, 2015), pp. 130-134.

[2] Michael C. Brower,Wind Resource Assessment, 1stedn. (John Wiley \& Sons,Inc., 2012).

[3] ZHAO Xiaowei, QI Xiuxiang, LIN Zhongqing, Wind Resource Assessment at Nansha District, Guangzhou, in Guangdong Meteorology, eds. Guangdong Meteorological Society, Vol.38, No.4 (2016), pp. 59-62.

[4] Goff and Gratch, Goff-Gratch equation, the 52nd annual meeting of the American Society of Heating and Ventilating Engineers(1946), https://en.wikipedia.org/wiki/Goff\%E2\%80\%93Gratch equation 